\title{
O magistério da educação básica paraibana no contexto das políticas educacionais
}

\author{
Rogério Fernandes Gurgel ${ }^{1}$ \\ rogeriofgurgel@yahoo.com.br
}

\begin{abstract}
Resumo
O contexto das reformas educacionais no país em anos recentes reflete, em parte, as lutas dos docentes pela melhoria das questões profissionais. Instituemse instrumentos para o ingresso e a permanência do professor no quadro do magistério público e medidas que versam sobre a formação continuada e remuneração. No entanto, falta um elo entre a definição e a implantação de uma política. No caso do magistério estadual da Paraíba, somente em 2003 foi aprovado o plano de carreira, apesar de vigorar uma política nessa direção desde 1996. O presente estudo, a partir da análise dos reajustes salariais ocorridos com a implantação do plano, evidencia as oscilações reais e projetivas da matriz salarial, fazendo o contraponto entre os indicadores deliberados pelo movimento docente e as políticas públicas definidas nacionalmente.
\end{abstract}

Palavras-chave: Carreira docente; Magistério; Políticas Educacionais.

\section{Introdução}

A definição de uma política pública que contemple a remuneração, a jornada de trabalho, as condições de exercício profissional e a formação continuada constituem consensos que há muito tempo demarcam pautas de documentos oficiais de governos, de representações sindicais e de

1 Doutorando em Educação pela Universidade Federal da Paraíba, Brasil. Estatutário da Prefeitura Municipal de Natal, Brasil. 
associações profissionais e entidades ligadas à educação, que por sua vez se expressam em normativas legais como Estatutos do Magistério e Planos de Carreira e Remuneração. Um plano de carreira deve ser concebido como um instrumento que estimule os profissionais do magistério a ingressarem e permanecerem no exercício da docência. Entretanto, o descompasso entre as medidas aprovadas nas diversas instâncias, onde as pautas discutidas estabelecem metas, e sua efetiva aplicação guardam distâncias por demais significativas. Nosso propósito é averiguar os efeitos de políticas de financiamento da educação e, de forma singular, categorias inerentes ao exercício da profissão docente, preocupação compartilhada por demais integrantes do Projeto de Pesquisa: Observatório da Educação “Remuneração dos professores das escolas públicas da educação básica: configurações, impactos, impasses e perspectivas" (CAPES/INEP/SECAD).

$\mathrm{O}$ instrumento que ora utilizamos constituiu-se de uma matriz salarial demonstrativa da dispersão na carreira docente, compreendendo os níveis de formação do professorado da rede estadual da Paraíba, comparando, em períodos específicos, o poder aquisitivo do professor frente ao salário mínimo necessário ${ }^{2}$, ao mesmo tempo em que situamos a posição salarial ocupada pelos docentes paraibanos em decorrência da aprovação do Piso Salarial Profissional Nacional (PSPN), regulamentado pela Lei no 11.738/2008 (BRASIL, 2008).

\section{$\mathrm{O}$ magistério público frente às políticas de financiamento}

Historicamente, a aspiração do magistério, em termos de valorização profissional, tem constituído a pauta de relatórios e documentos elaborados a partir de deliberações retiradas em eventos promovidos pelas entidades de classe representativas da categoria em nível nacional, regional, estadual ou municipal. Entre as deliberações, notadamente

2 [...] Salário mínimo fixado em lei, nacionalmente unificado, capaz de atender as suas necessidades vitais básicas e as de sua família, como moradia, alimentação, educação, saúde, lazer e, vestuário, higiene, transporte e previdência social, reajustado periodicamente, de modo a preservar o poder aquisitivo [...] (Constituição Federal de1988, Cap. II, Dos direitos sociais, art. $7^{\circ}$ - IV). 
ganharam destaque as que apontavam para um plano de carreira que contemplasse um piso salarial profissional nacional, como valor mínimo, que constituísse referência na elaboração das matrizes salariais do magistério da educação básica dos sistemas públicos de ensino; formação continuada, com afastamento periódico remunerado das atividades docentes e jornada de trabalho que incluísse momentos diferenciados para pesquisa, preparo de aulas, correção dos trabalhos dos alunos e interação com os demais segmentos da escola. Em meados dos anos de 1990, as aprovações da Lei de Diretrizes e Bases da Educação Nacional (LDB) - Lei no 9.394/1996 (BRASIL, 1996a) - e do Fundo de Manutenção e Desenvolvimento do Ensino Fundamental e de Valorização do Magistério (FUNDEF) - Lei no 9.424/1996 (BRASIL, 1996b) - refletiram essa discussão. Contudo, pela conjuntura neoliberal em que ocorreram, apresentaram um viés bastante restritivo e limitado, em particular pelo mencionado fundo contemplar somente uma das etapas da educação básica e quando comparados aos objetivos propostos inicialmente.

Como observaremos mais adiante, a evolução das receitas cresceu bastante; contudo, a permanência da Desvinculação dos Recursos da União (DRU) ${ }^{3}$, que retira $20 \%$ das receitas da educação, combinada com a política de isenção fiscal praticada por estados e municípios, com a manutenção do ensino superior das redes estaduais e municipais e com a inclusão da folha de pagamento dos docentes aposentados nos recursos vinculados, entre outros fatores, contribuíram para que as alterações constitucionais ocorridas não contemplassem devidamente o magistério com relação à remuneração pretendida, prometida e não cumprida pelo FUNDEF, considerando que o referido fundo consistia em uma política de descentralização de recursos e atribuições e que

3 Proposta de Emenda à Constituição (PEC) n. 96A/03 aprovada, reduz anualmente, a partir do exercício de 2009, o percentual da Desvinculação das Receitas da União (DRU) incidente sobre os recursos destinados à manutenção e ao desenvolvimento do ensino. Pela proposta, a alíquota que era de $20 \%$ cai para 12,5\% no exercício de 2009 e $5 \%$ em 2010. Em 2011, não haverá mais a incidência da DRU na educação. Com o fim da DRU para o setor, o Ministério da Educação passará a contar com cerca de $R \$ 9$ bilhões a mais por ano em seu orçamento, segundo informações da instituição. Hoje, a DRU retira $20 \%$ dos recursos destinados à educação, provenientes de arrecadação de tributos e contribuições federais. Embora o fim da desvinculação dos recursos para a educação só esteja previsto para ocorrer a partir de 2011, a PEC estabelece redução da DRU já em 2009 e 2010, liberando verbas extras de R \$ 4 bilhões e R 7 bilhões, respectivamente. (Agência Senado, 29/10/2009). 
dispunha de um mecanismo em que governos estaduais, municipais e a União contribuíssem com recursos financeiros para a composição do fundo, sendo que os estados, em sua maioria, em um volume maior do que a cota recebida devido ao número de matrículas no ensino fundamental da sua rede.

Como aconteceu em vários estados, na Paraíba, a instituição do FUNDEF não foi combinada com a aprovação de um plano de carreira, o que ocasionou a prática de abonos e rateios dos recursos, notadamente quando do fechamento dos balanços anuais, por força de um princípio previsto na normativa legal do referido fundo ${ }^{4}$.

Como já havíamos colocado, há um descompasso entre a definição de uma política e a sua efetivação plena. O caso da Paraíba é exemplar: somente após sete anos de vigência do FUNDEF é que o governo estadual instituiu, através da Lei no 7.419/2003 (PARAÍBA, 2003), o Plano de Cargos e Carreiras e Remuneração dos Profissionais da Educação do Estado da Paraíba (PCCR-PB).

\section{O enquadramento dos docentes no plano de carreira}

O mencionado plano organizou a carreira dos profissionais da educação enquadrando-os em três grupos que caracterizavam a situação dos professores em exercício na época da concepção do plano. Assim, os docentes concursados com formação pedagógica integraram o Quadro dos Efetivos.

Para atender a situação dos docentes que ingressaram na função sem ser pelo instrumento do concurso público há pelo menos cinco anos antes da vigência da Constituição Federal de 1988 - Ato das Disposições Constitucionais Transitórias, art.19 - (BRASIL, 1988), foi criado o Quadro Extraordinário e, por último, o Quadro Especial, para os contratados sem prévio concurso após a data da edição do plano de carreira, em 2003, e que, por isso, são despossuídos de estabilidade e não gozam

4 "Os recursos do fundo, incluída a complementação da União, quando for o caso, serão utilizados pelos Estados, Distrito Federal e Municípios, assegurados, pelo menos, $60 \%$ (sessenta por cento) para a remuneração dos profissionais do magistério, em efetivo exercício de suas atividades no ensino" $\left(\right.$ Lei n ${ }^{\circ} 9424 / 1996$, art. $^{\circ}$ ). 
das mesmas prerrogativas dos docentes que ingressaram pelas outras formas de provimento.

O PCCR-PB foi estruturado em classes correspondentes à ascensão vertical devido aos níveis de formação docente: o nível médio na modalidade normal, classe A; o nível superior em licenciatura plena, classe B; com especialização, classe C; com mestrado, classe D; com doutorado, classe E. As referências, representadas por algarismos romanos (de I a VII), designam a ascensão horizontal, à razão de 5\% a cada cinco anos de interstício, observados os critérios de desempenho, aperfeiçoamento profissional e domínio de conhecimentos pedagógicos na respectiva área de atuação.

Na mudança da classe A para a classe B, há um acréscimo de 15\%; para as classes subsequentes, 5\% a cada titulação (art.19, incisos I, II e III). Posteriormente, a diferença relativa entre as classes foi modificada, como veremos mais adiante. Os docentes que não possuíam formação pedagógica constituíram os cargos em extinção a partir da sua vacância.

O Piso Remuneratório do Professor Paraibano (PRP-PB) 5 era de $\mathrm{R} \$ 450,00$ para o docente com formação de nível médio na modalidade normal e jornada semanal de 25h. A jornada era distribuída com quatro quintos (4/5) de atividades diretas com os alunos (regência) e um quinto $(1 / 5)$ destinado às atividades daí decorrentes, como planejamento, preparação de aulas e cadernetas escolares, correção de trabalhos e provas, entre outras ações (Horas-Atividades). A TAB. 1, a seguir, exibe um comparativo entre a remuneração praticada e a dispersão remuneratória da carreira, com base na proposta original da categoria docente:

5 Constituído da somatória do vencimento de $\mathrm{R} \$ 300,00$ com a gratificação de $\mathrm{R} \$ 150,00$. 
TABELA 1

Matriz remuneratória praticada (PRP) x projetada (PSPN) - outubro 2003

\begin{tabular}{|c|c|c|c|c|}
\hline \multicolumn{2}{|c|}{ FORMAÇÃO-CARREIRA } & \multicolumn{2}{|c|}{ REMUNERAÇÃO (R\$) } & \multirow{2}{*}{$\begin{array}{c}\text { RAZÃO } \\
\text { PSPN/PRP-PB }\end{array}$} \\
\hline Classes & Referências & PRP-PB & PSPN-SMN & \\
\hline A & $\begin{array}{l}\text { Inicial } \\
\text { Média } \\
\text { Final }\end{array}$ & $\begin{array}{l}450,00 \\
517,50 \\
585,00\end{array}$ & $\begin{array}{l}1.392 \\
1.600 \\
1.808\end{array}$ & \multirow{5}{*}{3,09} \\
\hline B & $\begin{array}{l}\text { Inicial } \\
\text { Média } \\
\text { Final }\end{array}$ & $\begin{array}{l}517,50 \\
595,13 \\
672,75 \\
\end{array}$ & $\begin{array}{l}1.600 \\
1.840 \\
2.080 \\
\end{array}$ & \\
\hline C & $\begin{array}{l}\text { Inicial } \\
\text { Média } \\
\text { Final }\end{array}$ & $\begin{array}{l}540,00 \\
621,00 \\
702,00\end{array}$ & $\begin{array}{l}1.680 \\
1.932 \\
2.184 \\
\end{array}$ & \\
\hline $\mathrm{D}$ & $\begin{array}{l}\text { Inicial } \\
\text { Média } \\
\text { Final }\end{array}$ & $\begin{array}{l}562,50 \\
648,88 \\
731,25\end{array}$ & $\begin{array}{l}1.764 \\
2.028 \\
2.293\end{array}$ & \\
\hline $\mathrm{E}$ & $\begin{array}{l}\text { Inicial } \\
\text { Média } \\
\text { Final }\end{array}$ & $\begin{array}{l}585,00 \\
672,75 \\
760,50\end{array}$ & $\begin{array}{l}1.852 \\
2.130 \\
2.408\end{array}$ & \\
\hline
\end{tabular}

Fonte: Lei n ${ }^{\circ}$ 7.419/ 2003; DIEESE, 2009.

Na primeira coluna da TAB. 1, temos a distribuição por níveis de formação (classes); na segunda, as referências quando no ingresso, no meio e no final da carreira, relativas à evolução por avaliação de desempenho; já na terceira coluna, temos a remuneração praticada e, na quarta coluna, temos projetada a dispersão remuneratória da carreira com base na proposta original da categoria docente, definida e referendada em sucessivos congressos nacionais, que optou pelo Salário Mínimo Necessário $(\mathrm{SMN})^{6}$. Tal valor foi tomado como piso salarial do professor com formação de nível médio na modalidade normal e que cumprisse uma jornada de 40h semanais, dividida igualmente entre horas de regência e horas de atividades pedagógicas de formação, preparação e avaliação

6 Calculado mensalmente pelo Departamento Intersindical de Estatística e Estudos Socioeconômicos (DIEESE), tomando por base a variação mensal dos produtos de uma cesta básica alimentar formada por treze itens, ponderando-se, a partir dela, o SMN para cobrir o gasto mensal de uma família constituída de dois adultos e duas crianças. 
das atividades de sala de aula e de interação com os demais segmentos da escola. Observa-se, ainda na TAB. 1, a razão entre o valor projetado e o valor praticado. O resultado representa quantas vezes o primeiro é maior do que o segundo, ou seja, um pouco mais de três vezes $(3,09)$.

A proposta de um fundo de financiamento para toda a educação básica voltou a ser discutida, no Congresso Nacional, por iniciativa do Poder Executivo. Nesse percurso, a discussão enveredou pela Proposta de Emenda Constitucional (PEC), n 415/2005. A discussão foi permeada, por um lado, pela posição dos governos municipais de não comprometer os impostos de arrecadação própria com o fundo; por outro, pela posição dos governos estaduais, já penalizados pelo mecanismo imposto pelo FUNDEF que os obrigava a transferir recursos, originalmente destinados às suas redes de ensino, para as contas dos fundos das redes municipais de seu Estado.

Em maio de 2005, por sua vez, o Governo Estadual da Paraíba promoveu alterações importantes no PCCR-PB através da Lei $n^{\circ}$ 7.730/2005 (PARAÍBA, 2005). Além da evolução remuneratória, instituiu o Quadro Complementar, no qual os docentes foram enquadrados com vencimentos equivalentes aos dos docentes integrantes da classe B, referência inicial do quadro de provimento efetivo do magistério, contudo sem direito à evolução na carreira. Outra mudança introduzida foi o enquadramento dos regentes de ensino no Quadro Suplementar previsto no plano de carreira.

A TAB. 2, a seguir, configura a matriz da remuneração dos docentes. Como se pode observar, a matriz projetada a partir do valor do SMN de maio de 2005 mostra que ele é superior 3,44 em relação ao valor do PRP-PB, evidenciando rebaixamento do piso quando comparado a 2003, pois a sua diferença aumentou quase três vezes e meia. 
TABELA 2

Carreira e Remuneração: PRP-PB X PSPN - maio 2005

\begin{tabular}{|c|c|c|c|c|}
\hline \multicolumn{2}{|c|}{ FORMAÇÃO-CARREIRA } & \multicolumn{2}{|c|}{ REMUNERAÇÃO (R\$) } & RAZÃO \\
\hline Classes & Referências & PRP-PB & PSPN-SMN & PSPN/PRP-PB \\
\hline A & $\begin{array}{l}\text { Inicial } \\
\text { Média } \\
\text { Final }\end{array}$ & $\begin{array}{l}462,00 \\
531,30 \\
600,60\end{array}$ & $\begin{array}{l}1.588 \\
1.827 \\
2.101\end{array}$ & \multirow{5}{*}{3,44} \\
\hline B & $\begin{array}{c}\text { Inicial } \\
\text { Média } \\
\text { Final }\end{array}$ & $\begin{array}{l}531,30 \\
610.99 \\
690,69\end{array}$ & $\begin{array}{l}1.827 \\
2.101 \\
2.416\end{array}$ & \\
\hline $\mathrm{C}$ & $\begin{array}{c}\text { Inicial } \\
\text { Média } \\
\text { Final }\end{array}$ & $\begin{array}{l}554,40 \\
637,56 \\
720,72\end{array}$ & $\begin{array}{l}1.918 \\
2.206 \\
2.494\end{array}$ & \\
\hline $\mathrm{D}$ & $\begin{array}{c}\text { Inicial } \\
\text { Média } \\
\text { Final }\end{array}$ & $\begin{array}{l}577,50 \\
664,12 \\
750,75\end{array}$ & $\begin{array}{l}2.014 \\
2.317 \\
2.664\end{array}$ & \\
\hline E & $\begin{array}{c}\text { Inicial } \\
\text { Média } \\
\text { Final }\end{array}$ & $\begin{array}{l}600,60 \\
690,69 \\
780,78\end{array}$ & $\begin{array}{l}2.151 \\
2.432 \\
2.797\end{array}$ & \\
\hline
\end{tabular}

Fontes: Lei no 7.730/ 2005; DIEESE, 2009.

\section{A definição de uma nova política de financiamento}

Ao findar a vigência do FUNDEF, em 2006, foi promulgada a Medida Provisória $\mathrm{n}^{\mathrm{o}}$ 339/2006 (BRASIL, 2006), regulamentando o que fora previsto e acrescentando detalhes no que concerne à remuneração ${ }^{7}$, a quem são os profissionais do magistério da educação ${ }^{8}$ e ao significado de efetivo exercício?.

7 A referida MP define a remuneração como o total de pagamentos devidos aos profissionais do magistério da educação, em decorrência do efetivo exercício do cargo, emprego ou função, integrantes da estrutura, quadro ou tabela de servidores do Estado, Distrito Federal ou Município, conforme o caso, inclusive os encargos sociais incidentes. (MP n ${ }^{\circ} .339 / 06$, art.22-I).

8 Profissionais do magistério da educação são definidos na MP como os docentes e educadores que prestam suporte pedagógico direto ao exercício da docência, incluindo-se direção ou administração escolar, planejamento, inspeção, supervisão, orientação educacional e coordenação pedagógica. (MP n'. 339/06, art.22-II).

9 Efetivo exercício relaciona-se ao desempenho das atividades de magistério previstas no inciso II, associada à sua regular vinculação contratual, temporária ou estatutária com o ente governamental que o remunera, não sendo descaracterizado por eventuais afastamentos temporários previstos em lei, com ônus para o empregador, que não impliquem rompimento da relação jurídica existente. (MP $\mathrm{n}^{\circ} 339 / 06$, art.22-III). 
O ano de 2007 foi palco de debates envolvendo a União, as unidades federativas, as entidades educacionais representativas da sociedade civil e os parlamentares visando à definição e regulamentação de um fundo para a educação básica e, no seu bojo, a definição de um piso salarial nacional para o magistério. Por um lado, havia a proposta do movimento docente de um piso no valor do SMN; por outro, o Ministério da Educação (MEC) apresentou uma proposta de piso salarial de $\mathrm{R} \$ 850,00$ para uma jornada de 40h semanais, baseado no valor definido no acordo nacional de $1994^{10}$.

Por sua vez, a Confederação Nacional dos Trabalhadores em Educação (CNTE) apresentou uma proposta intermediária no valor do piso, ao mesmo tempo em que procurava resgatar a especificidade da carreira profissional em conformidade com a formação do docente: de $\mathrm{R} \$ 1.050,00$ para o docente de nível médio e de $\mathrm{R} \$ 1.575,00$ para o professor com licenciatura plena, vinculado à jornada de trabalho de $30 \mathrm{~h}$ semanais, como detalha a TAB. 3 :

TABELA 3

Propostas de PSPN ${ }^{11}$ : MEC X Movimento Docente - outubro 2007

\begin{tabular}{c|c|c|c|c}
\hline FORMAÇÃO - CARREIRA & \multicolumn{3}{|c}{ PROPOSTAS (R\$) } \\
\hline Classes & Referências & PSPN-MEC & PSPN-CNTE & PSPN-SMN \\
\hline A & I & 850 & 1.050 & 1.798 \\
\hline B & I & - & 1.575 & 2.696 \\
\hline
\end{tabular}

Fontes CNTE, 2007; DIEESE, 2009.

Observa-se, na TAB. 3, que a proposta do MEC representou menos da metade que a definida pelo movimento docente, além de não prever um valor para o docente com licenciatura plena (Classe B).

$10 \mathrm{Tal}$ acordo resultou na assinatura do Pacto pela Valorização do Magistério e Qualidade do Ensino, firmado entre o governo brasileiro e entidades representativas do magistério público e outras entidades educacionais. Para a efetivação desse pacto, entre governos e entidades educacionais, foi proposto um fundo nacional composto pelas verbas vinculadas constitucionalmente à educação básica envolvendo as três esferas governamentais. O Piso Salarial Profissional Nacional (PSPN) foi fixado em R $\$ 300,00$ em valores de julho de 1994. O valor do PSPN foi determinado pela razão entre as receitas disponíveis vinculadas à educação básica, número de matrículas e de professores necessários para atendê-las. 11 A proposta inicial encabeçada pelo MEC apontava para um piso de $R \$ 850,00$ e jornada de $40 \mathrm{~h}$ semanais. A contraproposta da CNTE apontava para uma carreira onde era estabelecido um piso para o nível médio e um valor para o docente com licenciatura plena com $50 \%$ a mais que o piso. 
No intuito de viabilizar a aprovação do piso, o Governo Federal elevou a proposta para R \$950,00, estabelecendo um canal de negociação com os entes federativos e entidades envolvidas no processo, o que resultou na aprovação da Lei $n^{\circ} 11.738 / 2008$ (BRASIL, 2008), que instituiu o PSPN. O valor inicial foi fixado em R $\$ 950,00$ para uma jornada semanal de 40h. Para jornadas diferenciadas deveria ser estabelecido um valor proporcional. A rede estadual de ensino da Paraíba praticava uma jornada de $25 \mathrm{~h}$, de forma que, para essa carga horária, o valor do piso ficaria reduzido para $\mathrm{R} \$ 593,75$.

Além disso, para 2009, a lei aprovada franqueou aos poderes públicos estaduais e municipais contabilizar, no cômputo do piso, os adicionais existentes. Como isto foi considerado, o magistério paraibano não teve, inicialmente, vantagem salarial alguma com o novo piso, pois, adicionando-se ao vencimento as gratificações ${ }^{12}$ pelo exercício da docência ou a gratificação pela função de suporte pedagógico (GED/ GEAP), o total final ultrapassava o piso nacional em 7,30\%. Tal percentual correspondia ao valor de $\mathrm{R} \$ 43,10$ para uma jornada de 25 horas e de $\mathrm{R} \$ 68,95$ para a jornada de $40 \mathrm{~h}$.

A vantagem mais significativa deveu-se à elevação em 60\% (de um quinto para um terço) nas horas-atividades dos docentes da rede estadual, por representar melhoria nas condições de trabalho e pelo fato do docente dispor de mais tempo para a preparação exigida ao exercício da docência. A TAB. 4, abaixo, simula a correlação entre jornadas e remuneração:

TABELA 4

PSPN X PRP-PB e Jornada do Magistério Paraibano - 2008

\begin{tabular}{c|c|c|c|c|c|c}
\hline \multirow{2}{*}{$\begin{array}{c}\text { JORNADA } \\
\text { SEMANAL }\end{array}$} & \multicolumn{3}{|c|}{ PSPN x JORNADA } & \multicolumn{3}{c}{$\begin{array}{c}\text { REMUNERAÇÃO - PB x } \\
\text { JORNADA }\end{array}$} \\
\cline { 2 - 7 } & $\mathbf{( R \$ )}$ & Regência & H-A & PRP - PB & Regência & H-A \\
\hline $25 \mathrm{~h}$ & 593,75 & $17 \mathrm{~h}$ & $08 \mathrm{~h}$ & 636,85 & $20 \mathrm{~h}$ & $05 \mathrm{~h}$ \\
$40 \mathrm{~h}$ & 950,00 & $28 \mathrm{~h}$ & $12 \mathrm{~h}$ & $1.018,95$ & $32 \mathrm{~h}$ & $08 \mathrm{~h}$ \\
\hline
\end{tabular}

Fontes: Lei n ${ }^{\circ}$ 11.738/08; SINTEP, 2008.

12 Valores relativos à remuneração, obtidos pelo somatório do vencimento com a Gratificação de Estímulo à Docência ou Gratificação de Atividades Pedagógicas (GED/GEAP), de valor correspondente ao percentual de $40 \%$ do vencimento. 
A TAB. 5, a seguir, compara a matriz remuneratória do magistério estadual da Paraíba para uma jornada de $25 \mathrm{~h}$ de trabalho semanal e o piso definido nacionalmente. Nela, a coluna 5 apresenta a concepção de piso definido pelo movimento docente no congresso nacional da categoria em 1989 e a sistematização da matriz salarial a partir do valor do piso atualizado até junho de 2008 pelo DIEESE. Na última coluna, temos a razão entre o piso reivindicado e o praticado, indicando que o piso reivindicado é 3,25 vezes maior que o efetivamente praticado:

TABELA 5

Piso Paraibano X PSPN X PISO-SMN - junho 2008

\begin{tabular}{|c|c|c|c|c|c|}
\hline \multicolumn{2}{|c|}{ FORMAÇÃO-CARREIRA } & \multicolumn{2}{|c|}{$\begin{array}{l}\text { REMUNERAÇÃO } \\
\text { (R\$) }\end{array}$} & \multirow{2}{*}{\begin{tabular}{|c|} 
REIVINDICADO \\
(R\$)
\end{tabular}} & \multirow{2}{*}{\begin{tabular}{|c|} 
RAZÃO \\
PSPN/ \\
PRP-PB
\end{tabular}} \\
\hline Classes & Referências & PRP-PB & PSPN & & \\
\hline Médio & $\begin{array}{c}\text { Inicial } \\
\text { Média } \\
\text { Final }\end{array}$ & $\begin{array}{l}636,85 \\
732,38 \\
827,90\end{array}$ & $\begin{array}{l}593,75 \\
682,81 \\
771,87\end{array}$ & $\begin{array}{l}2.072 \\
2.384 \\
2.695\end{array}$ & \\
\hline $\begin{array}{l}\text { Licenciatura } \\
\text { Plena }\end{array}$ & $\begin{array}{l}\text { Inicial } \\
\text { Média } \\
\text { Final }\end{array}$ & $\begin{array}{l}732,38 \\
842,24 \\
952,09\end{array}$ & $\begin{array}{l}682,80 \\
785,23 \\
887,66\end{array}$ & $\begin{array}{l}2.487 \\
2.860 \\
3.233\end{array}$ & \\
\hline Especialização & $\begin{array}{c}\text { Inicial } \\
\text { Média } \\
\text { Final }\end{array}$ & $\begin{array}{l}764,22 \\
878,85 \\
993,48\end{array}$ & $\begin{array}{l}712,50 \\
819,38 \\
926,25\end{array}$ & $\begin{array}{l}2.591 \\
2.980 \\
3.368\end{array}$ & 3,25 \\
\hline Mestrado & $\begin{array}{c}\text { Inicial } \\
\text { Média } \\
\text { Final }\end{array}$ & $\begin{array}{c}796,05 \\
915,46 \\
1.034,87\end{array}$ & $\begin{array}{l}742,21 \\
853,54 \\
964,87\end{array}$ & $\begin{array}{l}2.695 \\
3.099 \\
3.503\end{array}$ & \\
\hline Doutorado & $\begin{array}{c}\text { Inicial } \\
\text { Média } \\
\text { Final }\end{array}$ & $\begin{array}{c}827,90 \\
768,77 \\
1.076,28\end{array}$ & $\begin{array}{c}771,90 \\
887,69 \\
1.003,47\end{array}$ & $\begin{array}{l}2.802 \\
3.223 \\
3.643\end{array}$ & \\
\hline
\end{tabular}

Fontes: Lei n ${ }^{\circ}$ 11.738/08; SINTEP, 2008; DIEESE, 2008.

A remuneração do magistério paraibano, por sua vez, ultrapassou o piso remuneratório definido pela Lei $\mathrm{n}^{\circ}$ 11. 738/2008 em 7,30\%. Observa-se que houve uma queda do poder aquisitivo do docente, na medida em que se aprofundou a distância entre a remuneração e o salário mínimo necessário. Enquanto o SMN representava 3,09 vezes o 
piso remuneratório paraibano de 2003, em 2008 representou 3,25 vezes.

No final de 2008, o Governo Estadual da Paraíba promoveu alterações importantes no plano de carreira: elevou de $15 \%$ para $20 \%$, a diferença entre a remuneração do docente com nível médio e a remuneração do docente com licenciatura plena; ampliou a jornada de trabalho semanal para 30h, distribuindo 20h para interação direta com os alunos (Regência) e $10 \mathrm{~h}$ para atividades decorrentes da referida interação como, por exemplo, formação e atividades departamentais.

Os valores do PRP-PB em janeiro/ 2009 totalizaram 9,04\% a mais que o valor arbitrado pela Lei $\mathrm{n}^{\circ}$ 11.738/2008, conforme detalha a TAB. 6 :

TABELA 6

Comparativo da remuneração e jornada: PSPN X PRP-PB

Formação em nível médio na modalidade normal - janeiro 2009

\begin{tabular}{|c|c|c|c|c|c|c|}
\hline \multirow{2}{*}{$\begin{array}{l}\text { JORNADA } \\
\text { SEMANAL } \\
\text { (h) }\end{array}$} & \multirow{2}{*}{$\begin{array}{l}\text { PSPN } \\
\text { (R\$) }\end{array}$} & \multicolumn{2}{|c|}{$\begin{array}{l}\text { DISTRIBUIÇÃO } \\
\text { DA JORNADA } \\
\text { SEMANAL (h) }\end{array}$} & \multirow{2}{*}{$\begin{array}{c}\text { PRP-PB } \\
\text { (R\$) }\end{array}$} & \multicolumn{2}{|c|}{$\begin{array}{l}\text { DISTRIBUIÇÃO } \\
\text { DA JORNADA } \\
\text { SEMANAL (h) }\end{array}$} \\
\hline & & Regência & H-A & & Regência & H-A \\
\hline 30 & 712,50 & 20 & 10 & 776,93 & 20 & 10 \\
\hline 40 & 950,00 & 28 & 12 & $1.035,91$ & 28 & 12 \\
\hline
\end{tabular}

Fontes: Lei n ${ }^{\circ}$ 11.738/08; SINTEP, 2009.

Em maio de 2009, a remuneração do magistério paraibano obteve outro reajuste, continuando superior, com pouca margem, ao valor atualizado do PSPN. Enquanto o piso nacional foi definido em $\mathrm{R} \$ 849,30$ para uma jornada de $30 \mathrm{~h}$ semanais, o piso remuneratório do docente paraibano, com mesma jornada, foi elevado para $\mathrm{R} \$ 854,61$. Assim, comparando-se os anos de 2003 e de 2008, quando o SMN representava mais de três vezes o PRP-PB, com maio 2009, detecta-se que a distância entre eles reduziu-se para um pouco mais que duas vezes, evidenciando certo ganho na remuneração. Contudo, a distância entre a remuneração e o salário mínimo necessário ainda era mais que o dobro, como exibe a TAB. 7: 
TABELA 7

Magistério-PB X PSPN (original) - maio 2009

\begin{tabular}{|c|c|c|c|c|}
\hline \multicolumn{2}{|c|}{ FORMAÇÃO-CARREIRA } & \multicolumn{2}{|c|}{ REMUNERAÇÃO (R\$) } & \multirow{2}{*}{$\begin{array}{r}\text { RAZÃO } \\
\text { PSPN/ } \\
\text { PRP-PB }\end{array}$} \\
\hline Classes & Referências & PRP-PB & PSPN-SMN & \\
\hline Médio & $\begin{array}{c}\text { Inicial } \\
\text { Média } \\
\text { Final }\end{array}$ & $\begin{array}{c}854,61 \\
982,80 \\
1.110,99\end{array}$ & $\begin{array}{l}2.045 \\
2.352 \\
2.659\end{array}$ & \multirow{5}{*}{2,39} \\
\hline $\begin{array}{c}\text { Licenciatura } \\
\text { Plena }\end{array}$ & $\begin{array}{c}\text { Inicial } \\
\text { Média } \\
\text { Final }\end{array}$ & $\begin{array}{l}1.025,54 \\
1.179,37 \\
1.333,20\end{array}$ & $\begin{array}{l}2.352 \\
2.705 \\
3.057\end{array}$ & \\
\hline Especialização & $\begin{array}{c}\text { Inicial } \\
\text { Média } \\
\text { Final }\end{array}$ & $\begin{array}{l}1.068,27 \\
1.228,51 \\
1.388,74\end{array}$ & $\begin{array}{l}2.469 \\
2.840 \\
3.219\end{array}$ & \\
\hline Mestrado & $\begin{array}{c}\text { Inicial } \\
\text { Média } \\
\text { Final }\end{array}$ & $\begin{array}{l}1.111,01 \\
1.277,65 \\
1.444,31\end{array}$ & $\begin{array}{l}2.593 \\
2.982 \\
3.371\end{array}$ & \\
\hline Doutorado & $\begin{array}{c}\text { Inicial } \\
\text { Média } \\
\text { Final }\end{array}$ & $\begin{array}{l}1.153,74 \\
1.226,79 \\
1.499,86\end{array}$ & $\begin{array}{l}2.723 \\
3.131 \\
3.540\end{array}$ & \\
\hline
\end{tabular}

Fontes: Lei no 11.738/08; SINTEP, 2009; DIEESE, 2009.

O artigo $5^{\circ}$ da Lei $n^{\circ} 11.738 / 2008$ (BRASIL, 2008), que instituiu o Piso Salarial Profissional Nacional (PSPN), estabeleceu o mês de janeiro como o de sua atualização, utilizando-se, como critério, o mesmo percentual de crescimento do valor anual mínimo por aluno referente aos anos iniciais do ensino fundamental urbano, definido nacionalmente para o exercício seguinte, nos termos da Lei no 11.494/2007 (BRASIL, 2007), que instituiu o Fundo de Manutenção e Desenvolvimento da Educação Básica e de Valorização dos Profissionais da Educação (FUNDEB).

A Portaria Interministerial $n^{0}$ 1.227, de 31 de dezembro de 2009, (BRASIL, 2009) reajustou o valor mínimo do FUNDEB, para 2010, em $15,9358 \%$, o que levaria o valor do PSPN para R $\$ 1.312,85$. No entanto, o percentual que contemplou o piso foi rebaixado para $7,86 \%$, além do fato de incidir sobre o valor do piso de 2008 , de $\mathrm{R} \$ 950,00$, elevando-o 
para $\mathrm{R} \$ 1.024,67$. O MEC assim procedeu a partir de uma consulta feita à Advocacia Geral da União (AGU), cujo parecer julgou indevido o reajuste do piso, com base em 2009, por conta de uma Ação Direta de Inconstitucionalidade (ADI) ${ }^{13}$. A CNTE discordou do parecer da AGU, até porque a mencionada ADI, que ainda depende de julgamento do mérito, atém-se às questões de não considerar o piso como vencimento, mas como remuneração, inclusive valores pagos a qualquer título, como também as frações destinadas à distribuição da carga horária semanal prevista na Lei que instituiu o PSPN.

A discussão no plano nacional entre o valor oficial do PSPN e o defendido pela CNTE trouxe reflexos no plano local. No início de março próximo passado, antecedendo à decisão do MEC, o Governo Estadual da Paraíba reajustou o valor do piso em 5\% através da Medida Provisória $n^{\circ}$ 146/2010 (PARAÍBA, 2010a). Tal medida garantia o pagamento da diferença que por ventura existisse quando da definição do índice oficial para todo o país. Assim posto, ao final do mencionado mês, foi sancionada uma nova Medida Provisória, a de no 151/2010 (PARAÍBA, 2010b), assegurando ao piso local o percentual de 7,86\% retroagindo seus efeitos a partir de janeiro de 2010. Observa-se na TAB. 8, abaixo, que o valor do piso remuneratório definido oficialmente é inferior ao praticado na referida rede estadual. No entanto, ambos os valores são inferiores ao valor devido (piso legal).

TABELA 8

Comparativo: PSPN oficial $x$ Piso Paraibano

Formação em nível médio na modalidade normal - fevereiro 2011:

\begin{tabular}{c|c|c|c}
\hline $\begin{array}{c}\text { JORNADA SEMANAL } \\
\text { (h) }\end{array}$ & $\begin{array}{c}\text { PISO OFICIAL } \\
\text { (R\$) }\end{array}$ & $\begin{array}{c}\text { PISO PB } \\
\text { (R\$) }\end{array}$ & $\begin{array}{c}\text { PISO LEGAL } \\
\text { (R\$) }\end{array}$ \\
\hline 30 & 890,98 & 921,78 & $1.198,40$ \\
\hline 40 & $1.187,97$ & $1.229,04$ & $1.597,87$ \\
\hline
\end{tabular}

Fontes: Lei n 11.738/08; SINTEP, 2010; CNTE, 2011.

13 Trata-se da ADI n ${ }^{\circ} 4.167$ movida no Supremo Tribunal Federal (STF) contra a Lei que regulamentou o Piso Salarial Profissional Nacional do Magistério Público da Educação Básica pelos governadores dos estados do Rio Grande do Sul, Mato Grosso do Sul, Paraná, Santa Catarina e Ceará. 
Em maio de 2010, houve elevação do percentual entre as classes por meio da edição da Lei n.9.085/2010 (PARAÍBA, 2010c), passando a ter a seguinte diferença relativa, com vigência para dezembro de 2010, representando um aumento de $5 \%$ :

- Diferença entre as Classes A e B - 25\%

- Diferença entre as Classes A e C - 30\%

- Diferença entre as Classes A e D - 35\%

- Diferença entre as Classes A e E - 40\%

Assim, a matriz salarial atual tem uma configuração na qual o piso remuneratório de $\mathrm{R} \$ 921,78$ permanece e o teto vai para $\mathrm{R} \$ 1.677,64$, apresentando ligeira recuperação. Contudo, guardando uma distância de quase duas vezes e meia, quando comparado ao SMN, como indica a TAB. 9:

TABELA 9

Remuneração do Magistério Paraibano X PSPN - dezembro 2010

\begin{tabular}{|c|c|c|c|c|}
\hline \multicolumn{2}{|c|}{ FORMAÇÃO-CARREIRA } & \multicolumn{2}{|c|}{ REMUNERAÇÃO (R\$) } & \multirow{2}{*}{$\begin{array}{r}\text { RAZÃO } \\
\text { PSPN/ } \\
\text { PRP-PB }\end{array}$} \\
\hline Classes & Referências & PRP-PB & PSPN-SMN & \\
\hline A & $\begin{array}{l}\text { Inicial } \\
\text { Média } \\
\text { Final }\end{array}$ & $\begin{array}{c}921,78 \\
1.060,05 \\
1.198,31\end{array}$ & $\begin{array}{l}2.227,53 \\
2.561,66 \\
2.895,79\end{array}$ & \multirow{5}{*}{2,41} \\
\hline B & $\begin{array}{l}\text { Inicial } \\
\text { Média } \\
\text { Final }\end{array}$ & $\begin{array}{l}1.152,23 \\
1.325,06 \\
1.497,88\end{array}$ & $\begin{array}{l}2.784,41 \\
3.202,07 \\
3.619,74\end{array}$ & \\
\hline $\mathrm{C}$ & $\begin{array}{l}\text { Inicial } \\
\text { Média } \\
\text { Final }\end{array}$ & $\begin{array}{l}1.198,33 \\
1.378,07 \\
1.557,82\end{array}$ & $\begin{array}{l}2.895,79 \\
3.330,16 \\
3.764,53\end{array}$ & \\
\hline $\mathrm{D}$ & $\begin{array}{l}\text { Inicial } \\
\text { Média } \\
\text { Final }\end{array}$ & $\begin{array}{l}1.244,41 \\
1.431,08 \\
1.617,74\end{array}$ & $\begin{array}{l}3.007,17 \\
3.458,24 \\
3.909,32\end{array}$ & \\
\hline $\mathrm{E}$ & $\begin{array}{c}\text { Inicial } \\
\text { Média } \\
\text { Final }\end{array}$ & $\begin{array}{l}1.290,49 \\
1.484,06 \\
1.677,64\end{array}$ & $\begin{array}{l}3.118,54 \\
3.579,01 \\
4.054,10\end{array}$ & \\
\hline
\end{tabular}

Fontes: Lei no 11.738/08; SINTEP, 2010; Lei nº 9. 085/2010. 
A seguir, por meio da TAB. 10, compara-se a evolução do FUNDEF ao FUNDEB no Estado da Paraíba. Comparando-se o fluxo financeiro dos dois fundos, observa-se que enquanto o FUNDEF movimentou, em 2006, uma média mensal de 20,5 milhões, o FUNDEB, em 2009, movimentou uma média mensal de 48,8 milhões, portanto mais do que duplicou o volume de recursos financeiros movimentados; por outro lado, a aplicação na remuneração do magistério ultrapassou o percentual mínimo definido pela Lei no 11.494/2007 (BRASIL, 2007).

\section{TABELA 10}

Comparativo FUNDEF/FUNDEB no Estado da Paraíba - 2006 - 2009

\begin{tabular}{c|cc|cc|cc|cc}
\hline UF & \multicolumn{2}{|c|}{ FUNDEF - 06 } & \multicolumn{2}{|c|}{ FUNDEB - 07 } & \multicolumn{2}{c|}{ FUNDEB - 08 } & \multicolumn{2}{c}{ FUNDEB - 09 } \\
\hline \multirow{2}{*}{ PB } & M1 & R1\% & M2 & R2\% & M3 & R3\% & M4 & R4\% \\
\cline { 2 - 9 } & 20,5 & 63,7 & 28,1 & 69,8 & 38,7 & 63,9 & 48,8 & 67,3 \\
\hline
\end{tabular}

Fonte: Balanços anuais do Estado da Paraíba (2006, 2007, 2008, 2009).

Nota: M1, M2, M3 e M4 são as médias mensais anuais da movimentação financeira dos respectivos fundos, (em R\$ milhões); enquanto R1, R2, R3 e R4 representam o percentual gasto com a remuneração do magistério nos respectivos anos.

\section{Conclusão}

Há falta de uma política de financiamento que determine a participação de cada esfera pública, de forma proporcional ao potencial de arrecadação, na construção de um sistema nacional de educação que incorpore a educação na sua totalidade, abrangendo desde a creche à pós-graduação. A aprovação do fim da Desvinculação dos Recursos da União (DRU), mecanismo que retirava recursos da educação na ordem de 7 bilhões anuais, aponta, para os anos seguintes a 2011, a integralização de importantes recursos ao orçamento geral da educação.

O desvirtuamento de objetivos propostos pelos fundos educacionais focalizados tem sido prática comum. A valorização do magistério seria um deles, mas o simples fato de destinar o percentual de $60 \%$ dos recursos para a remuneração do magistério não garantiu melhoria salarial. Se 
por um lado, a inclusão das obrigações patronais e previdenciárias do magistério retira recursos da ordem de $10 \%$; por outro, a existência de fontes de financiamento da educação que não participam da composição dos fundos constitui elemento para se afirmar que, embora o crescimento da arrecadação de impostos contribua para a recuperação salarial do magistério da rede estadual, a pequena recuperação salarial repercutiu insuficientemente na melhoria do padrão de vida dos docentes, que continuam exercendo múltiplas jornadas de trabalho para sobreviver. 


\section{Referências}

ARELARO, Lisete Regina; GIL, Juca. Política de fundos na educação: duas posições. In: LIMA, Maria José Rocha; DIDONET, Vital (Orgs.) FUNDEB: avanços na universalização da educação básica. Brasília: Inep, 2006, p. 71-88.

BRASIL. Constituição (1988). Constituição da República Federativa do Brasil. Brasília: Senado Federal, 1988.

BRASIL. Lei n. 9.394 de 20 de dezembro de 1996. Dispõe sobre as diretrizes e bases da educação nacional. Diário Oficial da União, Brasília: v.135, n. 248, 23 dez. 1996a.

BRASIL. Lei n. 9.424 de 24 de dezembro de 1996. Dispõe sobre o Fundo de Manutenção e Desenvolvimento do Ensino Fundamental e de Valorização do Magistério, e dá outras providências. Diário Oficial da União, Brasília: n. 250, 26 dez. 1996b.

BRASIL. Proposta de Emenda Constitucional do Fundeb - PEC $n^{\circ} 415$ de junho de 2005. Brasília, 2005. Disponível em: <http:/ / www.planalto. gov.br/ccivil htm>. Acesso em: 18 jul. 2006.

BRASIL. Medida Provisória n. 339 de 28 de dezembro de 2006. Regulamenta o artigo 60 do Ato das Disposições Constitucionais Transitórias e dá outras providências. Disponível em: <http:/ /www. planalto.gov.br/ccivil. Htm>. Acesso em: 20 abr. 2007.

BRASIL. Lei n. 11.494 de 20 de junho de 2007. Dispõe sobre o Fundo de Manutenção e Desenvolvimento da Educação Básica e de Valorização dos Profissionais da Educação, na forma prevista no artigo 60 do Ato das Disposições Constitucionais Transitórias. Altera a Lei $\mathrm{n}^{\mathrm{0}} 10.195$, de 14 de fevereiro de 2001, revoga dispositivos das Leis $n^{\circ}$ 9. 424, de 24 de dezembro de 1996; da Lei $n^{\circ}$ 10.845, de 05 de 
março de 2000 e lei n ${ }^{\circ} 10.880$, de 09 de junho de 2004; e dá outras providências. Diário Oficial da União, Brasília: 21 jun. 2007.

BRASIL. Lei n. 11.738 de 16 de julho de 2008. Regulamenta a alínea " $\mathrm{e}$ " do inciso III do caput do art. $6^{\circ}$ do Ato das Disposições Constitucionais Provisórias, para instituir o piso salarial profissional nacional para os profissionais do magistério público da educação básica. Diário Oficial da União. Brasília, n. 136, 17 jul. 2008. Seção 1, p.1.

BRASIL. Portaria Interministerial n. 1.227 de 31 de dezembro de 2009. Fixa o custo aluno ano das etapas e modalidades da educação básica para o exercício de 2010, na forma prevista no art.15, III da Lei $\mathrm{n}^{\circ}$ 11.494/2007, e dá outras providências. Disponível em <http:/ /www. fnde.da.gov.br html>. Acesso em: 11 jan. 2010.

\section{CONFEDERAÇÃO NACIONAL DOS TRABALHADORES EM} EDUCAÇÃO. (CNTE) CNTE notícias. Brasília. Out. 2007. Disponível em: <http:/ / www.cnte.org.br>. Acesso em: 07 ago. 2009.

\section{CONFEDERAÇÃO NACIONAL DOS TRABALHADORES EM} EDUCAÇÃO. (CNTE) Boletim Semanal CNTE Informa 565. Brasília. fev. 2011. Disponível em: <http:/ / www.cnte.org.br>. Acesso em: 23 fev. 2011.

DEPARTAMENTO INTERSINDICAL DE ESTATÍSTICA E ESTUDOS SOCIOECONÔMICOS (DIEESE). Salário Mínimo Necessário. São Paulo: DIEESE, 2011. Disponível em: <http:/ / www.dieese.org.br>. Acesso em: 10 jan. 2011.

PARAÍBA. Controladoria Geral do Estado. Balanços Anuais: 2006, 2007, 2008 e 2009. Disponível em: <http:/ / www.siaf.cge.gov.br>. Acesso em: 22 nov. 2010.

PARAÍBA. Lei n. 7.419 de 15 de outubro de 2003. Dispõe sobre o Plano de Cargos, Carreira e Remuneração para o Grupo Ocupacional 
Magistério do Estado da Paraíba, e dá outras providências. Diário Oficial. João Pessoa: 16 out. 2003.

PARAÍBA. Lei n. 7.730 de 10 de maio de 2005. Dispõe sobre alterações de dispositivos legais da Lei $\mathrm{n}^{\circ} 7.419$, de 15 de outubro de 2003, que instituiu o Plano de Cargos, Carreira e Remuneração para o Grupo Ocupacional Magistério do Estado da Paraíba, e dá outras providências. Diário Oficial. João Pessoa: 11 maio 2005.

PARAÍBA. Medida Provisória n. 146 de 01 de março de 2010. Dispõe sobre a atualização do piso salarial do magistério público da educação básica do Estado da Paraíba e dá outras providências. Diário Oficial. João Pessoa: 02 mar. 2010a.

PARAÍBA. Medida Provisória n. 151 de 30 de março de 2010. Dispõe sobre a atualização do piso salarial do magistério público da educação básica do Estado da Paraíba e dá outras providências. Diário Oficial. João Pessoa: 31 mar. 2010b.

PARAÍBA. Lei n. 9.085, de 05 de maio de 2010. Dispõe sobre a atualização do piso salarial do magistério público da educação básica do Estado da Paraíba e dá outras providências. Diário Oficial. João Pessoa: 07 maio 2010c.

SINDICATO DOS TRABALHADORES EM EDUCAÇÃO DO ESTADO DA PARAÍBA (SINTEP). Informativo SINTEP, João Pessoa, ano 4, n. 05, maio 2008.

SINDICATO DOS TRABALHADORES EM EDUCAÇÃO DO ESTADO DA PARAÍBA (SINTEP). Informativo SINTEP, João Pessoa, ano 5, n. 08, abr. 2009.

SINDICATO DOS TRABALHADORES EM EDUCAÇÃO DO ESTADO DA PARAÍBA (SINTEP). Informativo SINTEP, João Pessoa, ano 6, abr. 2010. 


\title{
Basic education teaching in the state of Paraíba within the context of the educational policies
}

\begin{abstract}
The work analyzes Statutes and Plans Positions, Career and Remuneration (PCCRs) for basic education teachers in public schools of Brazil. This is a documentary research whose analysis leads to the exegesis of the regulatory own investigation. Were selected for analysis categories: a) type of admission / entry, access and insecurity; b) criteria for career advancement; c) license for continuing education d) distribution of Workdays; e) composition of compensation. The study found the growth of precarious forms of admission at the expense of public tender. Concerning to continuing formation, it is clear that there is a mismatch between the legal instruments relating to the license for absence from work, and the constraints imposed at the local level. The same notes with regard to career advancement. There was considerable heterogeneity regarding the remuneration both in regard to values about their own salary structure (bonuses). Moreover it was observed that the municipal capitals have better wage conditions that the state networks. But in general, the compensation feature is low compared to other professions that require the similar level.
\end{abstract}

Keywords: Career; Teaching; Remuneration.

Recebido: 18/01/2012

Aprovado: 24/06/2012 